\title{
Switchable bandstop to allpass filter using cascaded transmission line SIW resonators in K-band
}

\author{
A. A. Zolkefli' ${ }^{1}$, N. A. Shairi' ${ }^{2}$ B. H. Ahmad ${ }^{3}$, A. Othman ${ }^{4}$, N. Hassim ${ }^{5}$, Z. Zakaria ${ }^{6}$, I. M. Ibrahim ${ }^{7}$, \\ H. A. Majid $^{8}$ \\ 1,2,3,6,7 Microwave Research Group, Centre for Telecommunication Malaysia Research \& Innovation, Fakulti Kejuruteraan \\ Elektronik dan Kejuruteraan Komputer, Universiti Teknikal Malaysia Melaka, Hang Tuah Jaya, 76100, Durian Tunggal, \\ Melaka, Malaysia \\ ${ }^{4,5}$ Fakulti Teknologi Kejuruteraan Elektrik dan Elektronik, Universiti Teknikal Malaysia Melaka, Hang Tuah Jaya, \\ 76100, Durian Tunggal, Melaka, Malaysia \\ ${ }^{8}$ Faculty of Engineering Technology, Universiti Tun Hussein Onn Malaysia, Pagoh Campus, 84600, Pagoh, Johor, \\ Malaysia
}

\begin{tabular}{l} 
Article Info \\
\hline Article history: \\
Received Jan 26, 2021 \\
Revised May 20, 2021 \\
Accepted Jul 13, 2021 \\
\hline
\end{tabular}

\section{Keywords:}

Bandstop filter

Millimeter wave filter

Reconfigurable filter

SIW resonator

Switchable resonator

\begin{abstract}
In this paper, a switchable bandstop to allpass filter using cascaded transmission line SIW resonators is proposed. The switchable filter is performed by the switchable cascaded transmission line SIW resonators using discrete PIN diodes. Therefore, it can be used for rejecting any unwanted frequencies in the communication systems. The proposed filter design is operated in K-band and targeted for millimeter wave front end system for $5 \mathrm{G}$ telecommunication. Two filter designs with different orientation (design A and B) are investigated for the best performance and compact size. As a result, design $\mathrm{B}$ is the best by giving a maximum attenuation of $39.5 \mathrm{~dB}$ at $26.4 \mathrm{GHz}$ with the layout size of $33 \times 30 \mathrm{~mm}$.
\end{abstract}

This is an open access article under the $\underline{C C B Y-S A}$ license.

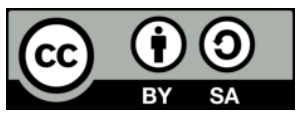

\section{Corresponding Author:}

Noor Azwan Shairi

Microwave Research Group, Centre for Telecommunication Research \& Innovation

Fakulti Kejuruteraan Elektronik dan Kejuruteraan Komputer (FKEKK), Universiti Teknikal Malaysia

Melaka, Hang Tuah Jaya, 76100, Durian Tunggal, Melaka, Malaysia

Email: noorazwan@utem.edu.my

\section{INTRODUCTION}

As modern wireless and microwave systems have advanced towards a spectral cognitive system, there will be a need for further filter reconfiguration to allow the full potential of this system performance such as 5G technology [1]-[3]. Reconfigurable filters including switchable and tunable filters have been of great interest because they were designed to be versatile wireless systems that capable of occupying different bandwidths, responses, and frequencies [4]-[10]. Therefore, RF front ends that need to accommodate changes in the spectrum and provide adaptive filtering can include a switchable, reconfigurable and tunable filters. One of the designs is focusing on the switchable bandstop to allpass filters [11]-[15], where it can be used for rejecting any unwanted frequencies in the communication systems. Besides, some traditional filter banks take much space to the circuit board which not suitable for integration and low-cost mass production [16] and therefore, most of the reconfigurable filter designs are using varactor diodes, PIN diodes or micro electromechanical systems (MEMs). Thus make it compact in size compared to the traditional filter banks. 
On the other hand, substrate integrated waveguide (SIW) is found to be a suitable choice in microwave and millimeter wave for designing and developing the components such as antenna [17], filter [18] and power divider [19]. As reported in [16], there are advantages of SIW over the conventional metallic waveguides such as low loss and high-quality factor for SIW cavities, permanent electrical isolation due to the shielding via posts, high power handling and the integrability capabilities of SIW structures with all sorts of passive and active components. As reported by previous researchers in [20]-[23], most of the reconfigurable filter designs using SIW are either for bandstop filter or bandpass filter.

Therefore, this paper proposes a switchable bandstop to allpass filter using cascaded transmission line SIW resonator. The switchable filter is performed by the switchable cascaded transmission line SIW resonators using discrete PIN diodes. The design consists of four cascaded SIW resonators and it is operated in K-band. The proposed filter is targeted for millimeter wave front end system for $5 \mathrm{G}$ telecommunication. Two filter designs with different orientation (design A and B) are investigated for the best performance and compact size. Beside that, in this paper, a tapered microstrip transition and rectangle microstrip transition are investigated for the best performance in this filter design.

\section{CIRCUIT DESIGN OF SWITCHABLE BANDSTOP TO ALLPASS FILTER}

\subsection{Switchable transmission line siw resonator}

The switching element of the SIW resonator in Figure 1 is performed by using a discrete PIN diode to allow the switching between bandstop and allpass responses. The bandstop of the resonator is operated due to the resonant frequency of a quarter wavelength $(\lambda / 4)$ of the open stub of the SIW transmission line. The PIN diode is operated by two different states which are ON state and OFF state. For OFF state and ON state of the PIN diode, the voltage supplies are $+5 \mathrm{~V}$ and $-5 \mathrm{~V}$ respectively. The resonator's switchable operation is explained as follows. The PIN diode of the SIW resonator is supplied with $+5 \mathrm{~V}$ (OFF state), which allows allpass response and is supplied with $-5 \mathrm{~V}$ (ON state) for switching to a bandstop response. In the SIW structure, via holes form a major part of the SIW to realize the bilateral edge walls. Via holes are the most important discontinuities in multilayered circuits. Therefore, in designing via holes of the SIW, the following in [24] and [25] are used,

$$
\begin{aligned}
& \lambda_{g}=\frac{2 \pi}{\sqrt{\frac{\varepsilon_{r}(2 \pi f)^{2}}{c^{2}}-\left(\frac{\pi}{a}\right)^{2}}} \\
& d<\frac{\lambda_{g}}{5} \\
& p \leq 2 d
\end{aligned}
$$

Where $\lambda_{g}$ is the guided wavelength, $d$ is the diameter of the via and $p$ is the pitch between the via. Take note that, (2) and (3) are used to ensure that the radiation leakage will be maintained at a very low amount and with that, SIW can be designed almost similar to the conventional rectangular waveguide with the appropriate dimension of $d$ and $p$.

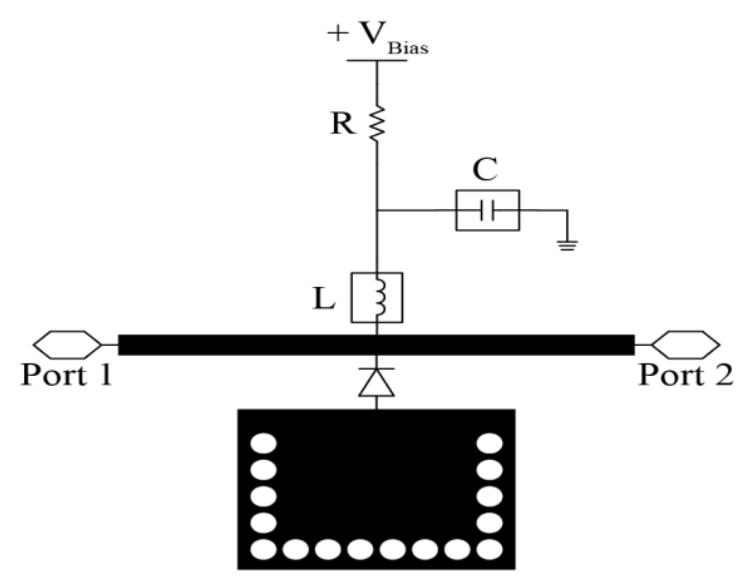

Figure 1. Switchable transmission line SIW resonator 


\subsection{SIW Resonator with microstrip transition}

In order to combine the SIW and microstrip transmission lines, SIW to microstrip transitions are required [26]-[29]. The design of this transition is very critical and important to achieve a good performance of the filter design. In order to fine the best transition, this paper investigates the tapered microstrip transition and rectangle microstrip transition. Therefore, (4) is used to determine the width of the transition [30]:

$$
Z_{1}=Z_{0} Z_{2}
$$

By using (4), we can design the microstrip transition accordingly as shown in Figure 2 (a) and 2 (b). Both circuit designs consist of tapered and rectangle microstrip lines section that connected to $50 \Omega$ impedance of microstrip line and SIW resonator.

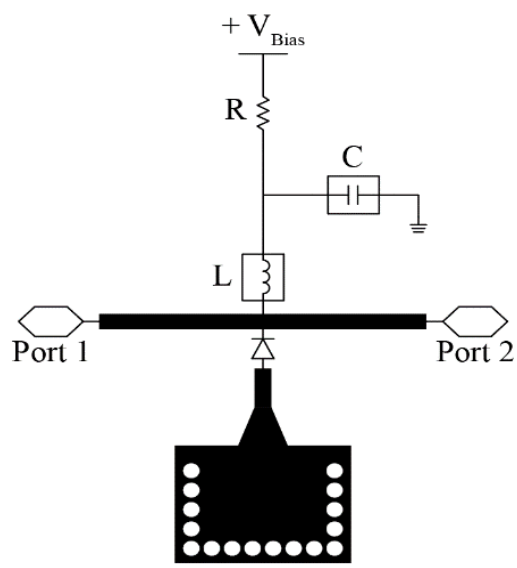

(a)

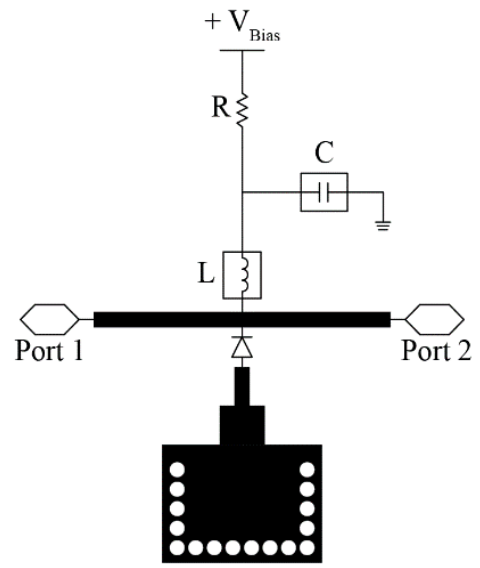

(b)

Figure 2. Switchable SIW resonator with; (a) tapered microstrip transition, (b) rectangle microstrip transition

\subsection{Cascaded switchable transmission line SIW resonators}

Two circuits of bandstop to allpass reconfigurable filter with four cascaded switchable SIW resonators (S1, S2, S3 and S4) are illustrated in Figure 3 (a) and 3 (b) for design A and B respectively. The proposed filter circuits were constructed in CST software. All the Roger RT/duroid 5880 substrate parameters such as thickness of $0.254 \mathrm{~mm}$ and relative dielectric constant of 2.2 were included in the filter design. The proposed design was simulated with ideal PIN diodes which are open circuited for OFF state and short circuited for ON state.

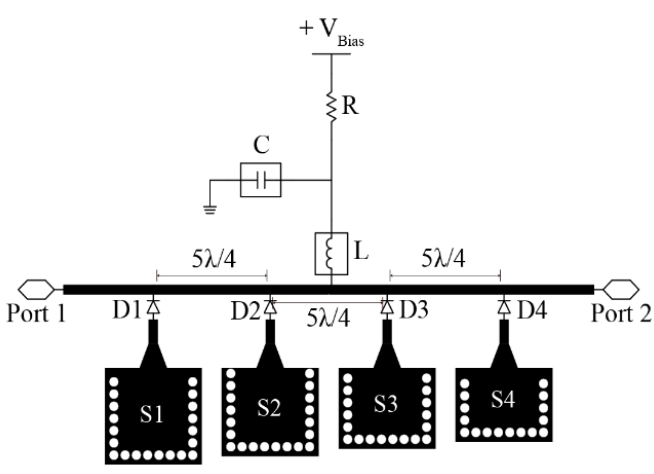

(a)

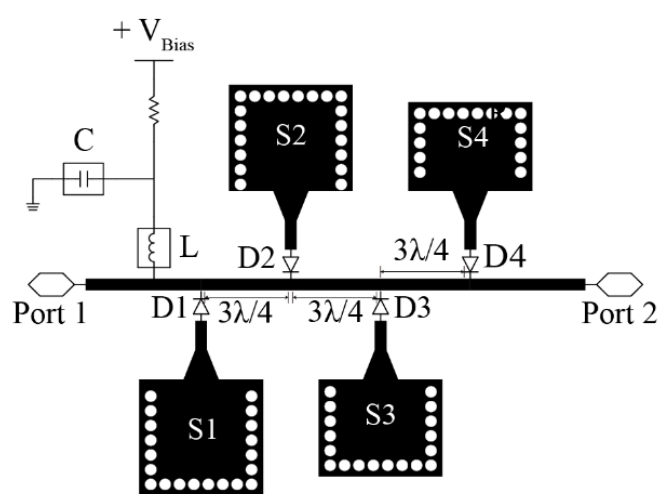

(b)

Figure 3. Switchable bandstop to allpass filter of, (a) design A, (b) design B

The resonators of S1, S2, S3 and S4 are resonated at 24.25, 25.33, 26.42 and $27.5 \mathrm{GHz}$ respectively in K-band. Each resonator is ideally controlled using PIN diodes (D1, D2, D3 and D4). These resonant 
frequencies are expected to cover for $5 \mathrm{G}$ telecommunication in $26 \mathrm{GHz}$ band [31]. Besides, the design can be used in RF switch circuit as reported in [32]-[34]. Both designs in Figure 3 (a) and 3 (b) has different length

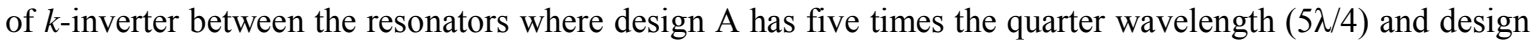
$\mathrm{B}$ has three times the quarter wavelength (3N/4). Consequently, the total size of design $\mathrm{A}$ is $44 \times 30 \mathrm{~mm}$ while the total size of design $\mathrm{B}$ is $33 \times 30 \mathrm{~mm}$ where the circuit design $\mathrm{B}$ is smaller size compared to design A. Design B was selected for verification and thus was fabricated as a prototype as depicted in Figure 4. The prototype is without PIN diodes where it was measured as an ideal PIN diode as same as in the simulation in the CST software. As shown in Figure 4, it is an open circuited for OFF state for allpass response. For bandstop response, a copper tape was used as a short circuited for ON state.

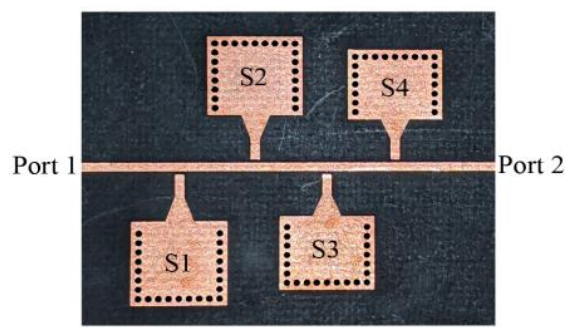

Figure 4. Prototype of design B (dimension: $33 \times 30 \mathrm{~mm})$

\section{RESULTS AND DISCUSSION}

\subsection{Switchable transmission line SIW resonators with microstrip transition}

The simulation results of transition design in Figure 2 (a) and 2 (b) are compared in this section in order to find the best transition. The circuit configuration for both designs were simulated with the length of microstrip transition, $l_{\text {Transition }}=1.95 \mathrm{~mm}(\lambda / 4)$, length of the SIW resonator, $l_{\mathrm{SIW}}=4.8 \mathrm{~mm}$ (resonated at $27.5 \mathrm{GHz}$ ), the diameter of the via, $d=0.75 \mathrm{~mm}$ and the pitch between the via, $p=1.0 \mathrm{~mm}$. Take note that the simulation was done by using ideal PIN diode as discussion in section 2.

Figure 5 (a) and 5 (b) show the allpass response and Figure 6 (a) and 6 (b) show the bandstop response for both tapered microstrip transition and rectangle microstrip transition. In Figure 5 (a), the return loss (S11) for both transitions achieved more than $10 \mathrm{~dB}$ at $27.5 \mathrm{GHz}$. Meanwhile, the insertion loss (S21) in Figure 5 (b) also produced the same result for both transitions which was less than $0.5 \mathrm{~dB}$ at $27.5 \mathrm{GHz}$.

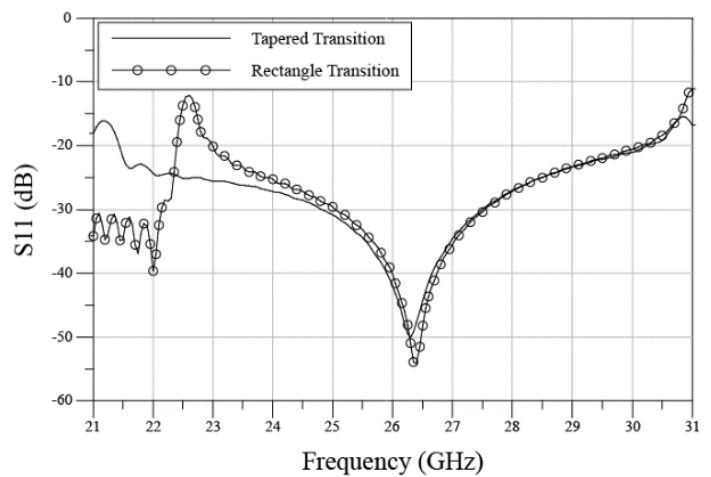

(a)

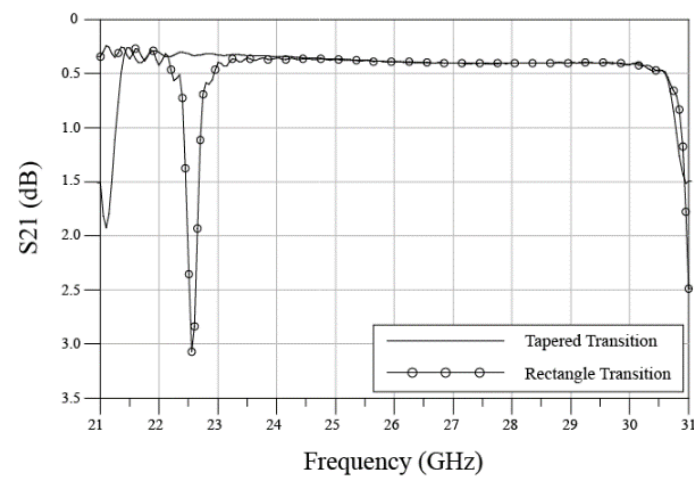

(b)

Figure 5. Allpass response for; (a) return loss, (b) insertion loss of SIW resonator with different microstrip transitions

Figure 6 (a) is the result of return loss (S11) for bandstop response for both circuit designs. The tapered microstrip transition achieved S11 less than $1 \mathrm{~dB}$ while the rectangle microstrip transition achieved S11 more than $1 \mathrm{~dB}$ at $27.5 \mathrm{GHz}$. In Figure 6 (b), the maximum attenuation (S21) showed that the tapered microstrip transition and rectangle microstrip transition achieved 27 and $21.5 \mathrm{~dB}$ respectively at $27.5 \mathrm{GHz}$. The SIW resonator with tapered microstrip transition has a slight wider bandwidth of around $2 \mathrm{GHz}$ (at 
$-3 \mathrm{~dB}$ ) compared to the rectangle microstrip transition which was $1.7 \mathrm{GHz}$ bandwidth. Table 1 shows the circuit performance comparison for the return loss and insertion loss (of allpass response); and return loss and attenuation (of bandstop response) for the tapered and rectangle microstrip transitions. Therefore, it was found that the switchable SIW resonator with tapered microstrip transition gave a better performance compared to the rectangle microstrip transition. Thus, the next performance analysis of design A and B is based on the tapered microstrip transition.

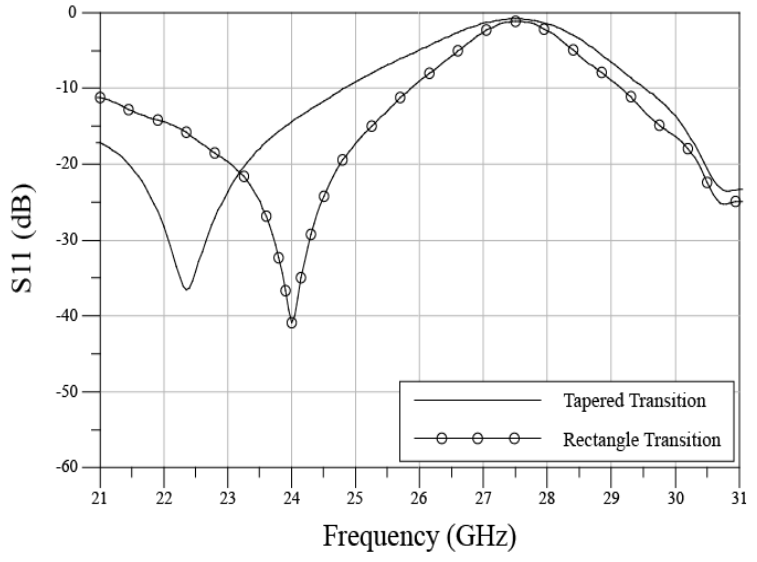

(a)

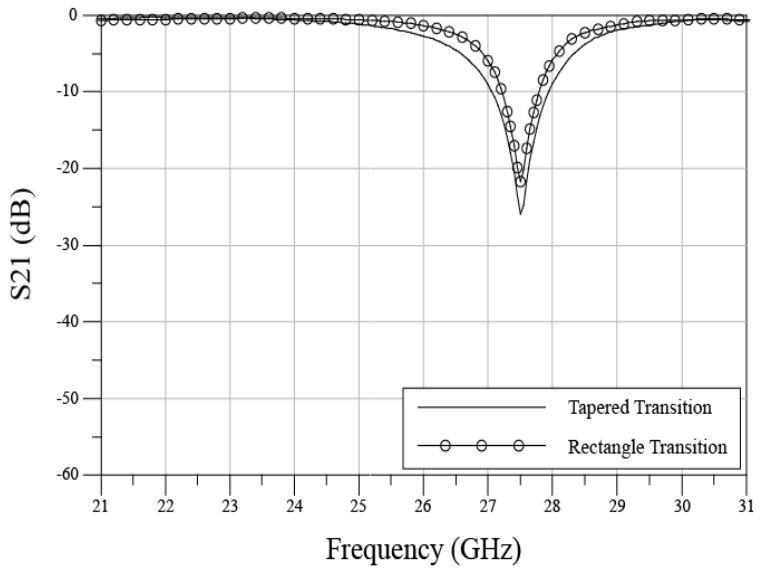

(b)

Figure 6. Bandstop response of; (a) return loss, (b) attenuation of SIW resonator with different microstrip transitions

Table 1. Comparison of SIW resonator between tapered and rectangle microstrip transitions

\begin{tabular}{ccccc}
\hline & $\begin{array}{c}\text { Return Loss } \\
\text { (Allpass response) } \\
@ 27.5 \mathrm{GHZ}\end{array}$ & $\begin{array}{c}\text { Return Loss (Bandstop } \\
\text { response) @ 27.5 GHz }\end{array}$ & $\begin{array}{c}\text { Insertion Loss } \\
\text { (Allpass response) } \\
\text { @ 27.5 GHz }\end{array}$ & $\begin{array}{c}\text { Attenuation (Bandstop } \\
\text { response) } \\
@ 2 ~ 27.5 \mathrm{GHz}\end{array}$ \\
\hline $\begin{array}{c}\text { Tapered microstrip } \\
\text { transition }\end{array}$ & $>10 \mathrm{~dB}$ & $<1 \mathrm{~dB}$ & $<.5 \mathrm{~dB}$ & $27 \mathrm{~dB}(\mathrm{max})$ \\
$\begin{array}{c}\text { Rectangle microstrip } \\
\text { transition }\end{array}$ & $>10 \mathrm{~dB}$ & $>1 \mathrm{~dB}$ & $<0.5 \mathrm{~dB}$ & $21.5 \mathrm{~dB}(\mathrm{max})$ \\
\hline
\end{tabular}

\subsection{Cascaded switchable transmission line SIW resonators}

After considering the performance analysis of microstrip transition in the filter design, the circuit's design parameters for design A and B are summarized in Table 2. Take note that the simulation performance for design A and B was done by using ideal PIN diode as discussed in section 2.

Table 2. Design parameters of design A and B

\begin{tabular}{|c|c|c|c|c|c|c|c|c|}
\hline & $\begin{array}{l}\text { Length of } \\
\mathrm{S} 1, l_{\mathrm{S} 1}\end{array}$ & $\begin{array}{l}\text { Length of } \\
\mathrm{S} 2, l_{\mathrm{S} 2}\end{array}$ & $\begin{array}{l}\text { Length of } \\
\mathrm{S} 3, l_{\mathrm{S} 3}\end{array}$ & $\begin{array}{l}\text { Length of } \\
\mathrm{S} 4, l_{\mathrm{S} 4}\end{array}$ & $\begin{array}{l}\text { Width of SIW } \\
\text { resonator, } W_{\text {SIW }}\end{array}$ & $\begin{array}{l}\text { Length between } \\
\text { SIW resonator, } l\end{array}$ & $\begin{array}{l}\text { Diameter of } \\
\text { the via, } d\end{array}$ & $\begin{array}{l}\text { Pitch between } \\
\text { the via, } p\end{array}$ \\
\hline Design A & $6.62 \mathrm{~mm}$ & $5.95 \mathrm{~mm}$ & $5.35 \mathrm{~mm}$ & $4.8 \mathrm{~mm}$ & & $9.75 \mathrm{~mm}(5 \lambda / 4)$ & & \\
\hline Design $B$ & $\begin{array}{c}\text { (resonate } \\
\text { at } 24.25 \\
\mathrm{GHz} \text { ) }\end{array}$ & $\begin{array}{c}\text { (resonate } \\
\text { at } 25.33 \\
\mathrm{GHz} \text { ) }\end{array}$ & $\begin{array}{c}\text { (resonate } \\
\text { at } 26.42 \\
\mathrm{GHz} \text { ) }\end{array}$ & $\begin{array}{c}\text { (resonate } \\
\text { at } 27.5 \\
\mathrm{GHz} \text { ) }\end{array}$ & $5.822 \mathrm{~mm}$ & $5.85 \mathrm{~mm}(3 \lambda / 4)$ & $0.75 \mathrm{~mm}$ & $1.0 \mathrm{~mm}$ \\
\hline
\end{tabular}

The circuits (design A and B) were simulated in terms of insertion loss (S21 of allpass response), attenuation (S21 of bandstop response) and insertion loss (S11). Figure 7 and 8 show the simulation results of allpass and bandstop responses respectively for design A and B. Figure 7 (a) and 7 (b) are the return loss (S11) and insertion loss (S21) respectively for both circuit designs. The return loss (S11) in Figure 7 (a) during allpass response for design A and design B achieved more than $14.4 \mathrm{~dB}$ and $13.9 \mathrm{~dB}$ respectively from 24.25 to $27.5 \mathrm{GHz}$. Meanwhile, in Figure 7 (b), the insertion loss (S21) during allpass response achieved a similar result from 24.25 to $27.5 \mathrm{GHz}$ which was less than $2 \mathrm{~dB}$. 


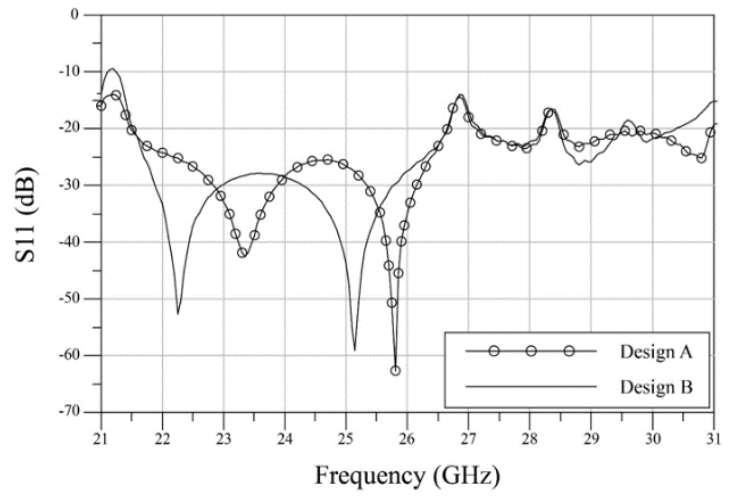

(a)

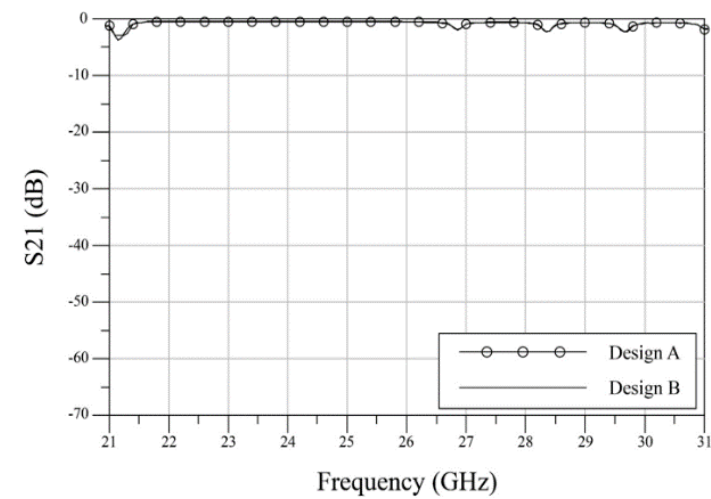

(b)

Figure 7. Allpass response of; (a) return loss, (b) insertion loss for design A and B

As shown in Figure 8 (a) and 8 (b), the return loss (S11) and attenuation (S21) for bandstop response of design A and B are plotted and compared. In Figure 8 (a), the return loss (S11) of design A and B achieved the same result which was less than $2.4 \mathrm{~dB}$ from 24.25 to $27.5 \mathrm{GHz}$. As shown in Figure 8 (b), the attenuation performance (from 24.25 to $27.5 \mathrm{GHz}$ ) of design A was $10 \mathrm{~dB}$ (min) and $37 \mathrm{~dB}$ (max); and for design $\mathrm{B}$ was $13.3 \mathrm{~dB}(\min )$ and $40 \mathrm{~dB}$ (max). The bandwidth of design $\mathrm{B}$ was $4 \mathrm{GHz}($ at $-3 \mathrm{~dB})$ and wider than the bandwidth of design A which was $3.8 \mathrm{GHz}$ (at $-3 \mathrm{~dB}$ ). The comparison between design $\mathrm{A}$ and $\mathrm{B}$ for the return loss and insertion loss (of allpass response); and return loss and attenuation (of bandstop response) are listed in Table 3.

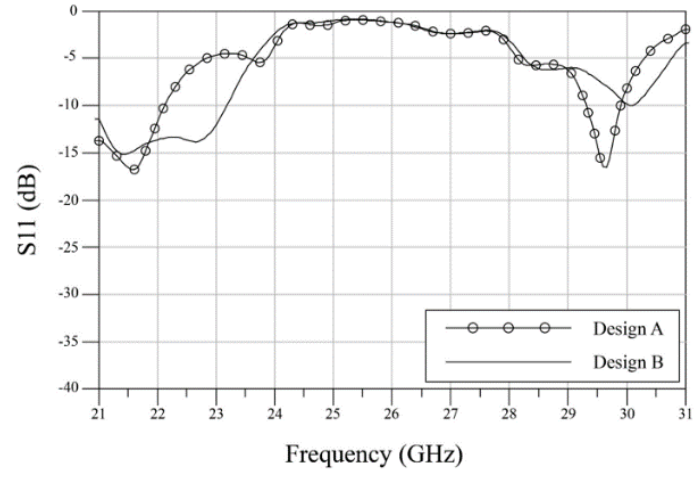

(a)

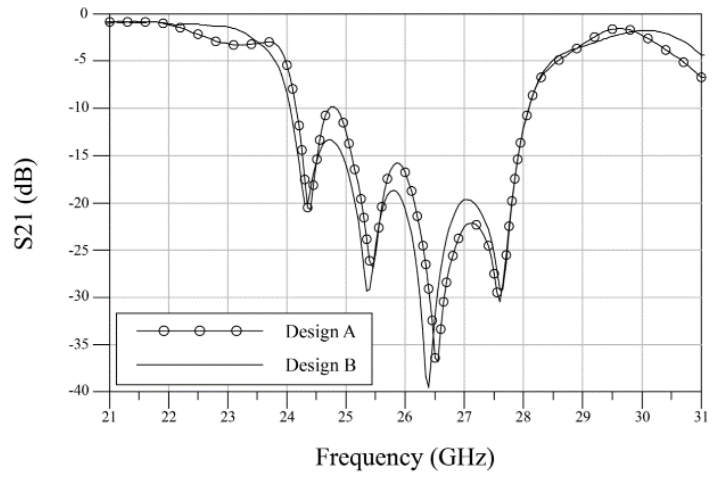

(b)

Figure 8. Bandstop response of; (a) return loss, (b) attenuation for design A and design B

Table 3. Performance comparison between design A and design B

\begin{tabular}{ccccc}
\hline & $\begin{array}{c}\text { Return loss } \\
\text { (allpass respons) @ } \\
24.25-27.5 \mathrm{GHz}\end{array}$ & $\begin{array}{c}\text { Return loss } \\
\text { (bandstop respons) @ } \\
24.25-27.5 \mathrm{GHz}\end{array}$ & $\begin{array}{c}\text { Insertion loss } \\
\text { (allpass response) @ } \\
24.25-27.5 \mathrm{GHz}\end{array}$ & $\begin{array}{c}\text { Attenuation } \\
\text { (bandstop response) @ } \\
24.25-27.5 \mathrm{GHz}\end{array}$ \\
\hline Design A & $>14.4 \mathrm{~dB}$ & $<2.4 \mathrm{~dB}$ & $<2 \mathrm{~dB}$ & $10 \mathrm{~dB}(\min )$ \\
& & & & $37 \mathrm{~dB}(\max )$ \\
Design B & $>13.9 \mathrm{~dB}$ & $<2.4 \mathrm{~dB}$ & $<2 \mathrm{~dB}$ & $13.3 \mathrm{~dB}(\min )$ \\
& & & $40 \mathrm{~dB}(\max )$ \\
\hline
\end{tabular}

Figure 9 shows the performance comparison between measurement and simulation results of design B for allpass and bandstop responses. Design B was selected for fabrication since it produced the best performance result of attenuation (S21) and smaller size compared to design A. The measurement was done using a network analyzer to verify with the simulation result. Therefore, Figure 9 (a) shows the comparison of the measurement and simulation of allpass response for return loss and insertion loss. The measured return loss of design B was more than $13.9 \mathrm{~dB}$. On the other hand, the measured insertion loss of design B was less 
than $2.2 \mathrm{~dB}$. In Figure 9 (a), the measured result for the insertion loss managed to achieve almost similar with simulated result, while the return loss was noticed that the performance dropped significantly compared to the simulated result. Figure 9 (b) shows the performance comparison of the measurement and simulation results of design $B$ for bandstop response. The measured return loss was less than $9.5 \mathrm{~dB}$. Meanwhile, the measured attenuation for design $\mathrm{B}$ was achieving a minimum value of $14.8 \mathrm{~dB}$ and maximum value of 39.5 $\mathrm{dB}$ (from 24.25 to $27.5 \mathrm{GHz}$ ). In Figure 9 (b), the measured attenuation was shifted around $1 \mathrm{GHz}$ and the performance of the return loss was dropped a bit compared to the simulated result. However, in general, it was observed that the measured results were correlated with the simulated results. Table 4 summarized the performance comparison between measurement and simulation results of design B. In future work, the proposed design will be fabricated with actual PIN diode and measured for verification. Then it will be integrated with millimeter wave antennas [35], [36] for any millimetre wave applications.

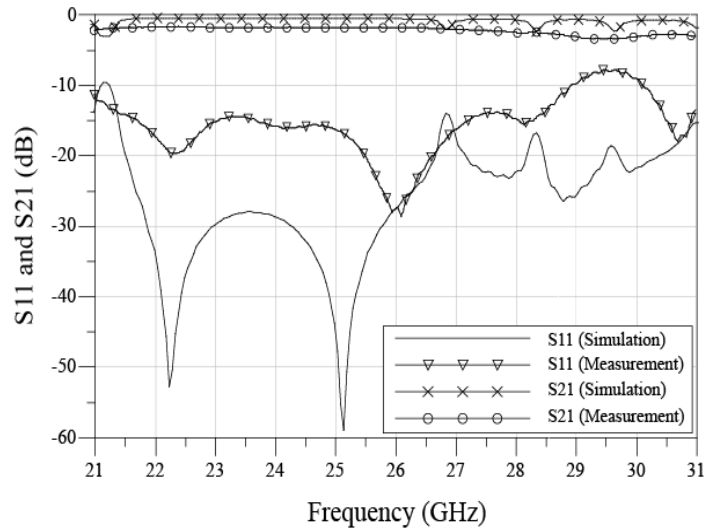

(a)

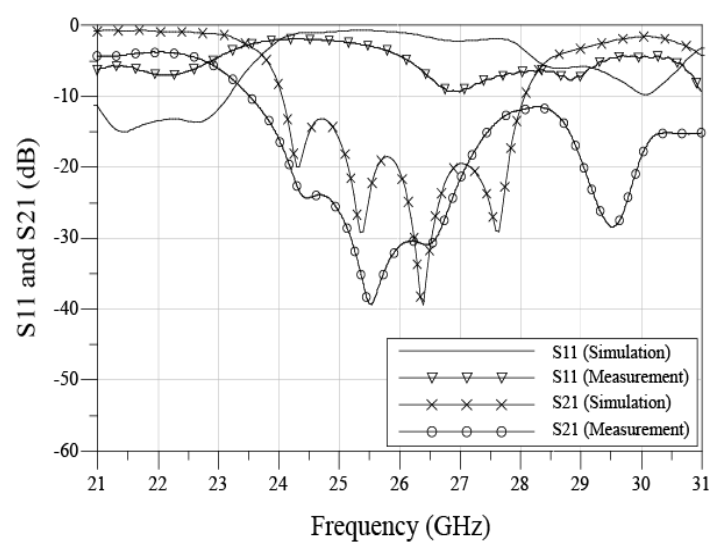

(b)

Figure 9. Measurement versus simulation of design B for, (a) allpass, (b) bandstop responses

Table 4. Performance comparison of measurement and simulation results of design B

\begin{tabular}{|c|c|c|c|c|}
\hline & $\begin{array}{c}\text { Return loss } \\
\text { (allpass response) @ } \\
24.25-27.5 \mathrm{GHz}\end{array}$ & $\begin{array}{c}\text { Return loss } \\
\text { (bandstop response) @ } \\
24.25-27.5 \mathrm{GHz}\end{array}$ & $\begin{array}{c}\text { Insertion loss } \\
\text { (allpass response) @ } \\
24.25-27.5 \mathrm{GHz}\end{array}$ & $\begin{array}{c}\text { Attenuation } \\
\text { (bandstop response) @ } \\
24.25-27.5 \mathrm{GHz}\end{array}$ \\
\hline Simulation result & $>13.9 \mathrm{~dB}$ & $<2.4 \mathrm{~dB}$ & $<2 \mathrm{~dB}$ & $\begin{array}{l}13.5 \mathrm{~dB}(\min ) \\
39.5 \mathrm{~dB}(\max )\end{array}$ \\
\hline $\begin{array}{l}\text { Measurement } \\
\text { result }\end{array}$ & $>13.9 \mathrm{~dB}$ & $<9.5 \mathrm{~dB}$ & $<2.2 \mathrm{~dB}$ & $\begin{array}{l}14.8 \mathrm{~dB}(\min ) \\
39.5 \mathrm{~dB}(\max )\end{array}$ \\
\hline
\end{tabular}

\section{CONCLUSION}

The proposed switchable bandstop to allpass filter using cascaded transmission line SIW resonator was succesfully designed and simulated in CST software. It was designed in K-band for millimeter wave application. First, for the analysis of SIW to microstrip line transition, it was found that the switchable SIW resonator with tapered microstrip transition gave a better performance compared to the rectangle microstrip transition. Second, two filter designs with different orientation (design A and B) were investigated for the best performance and compact size. Then, design B was fabricated for measurement and verification with simulated results. As a result, design $\mathrm{B}$ is the best by giving a maximum attenuation of $39.5 \mathrm{~dB}$ at $26.4 \mathrm{GHz}$ with the layout size of $33 \times 30 \mathrm{~mm}$.

\section{ACKNOWLEDGEMENTS}

The authors would like to greatly express their thanks and appreciation to the Centre for Research and Innovation Management (CRIM) and Universiti Teknikal Malaysia Melaka (UTeM) for their encouragement and help to complete this research work. This work was supported by Ministry of Higher Education (MOHE) under the research grant no: FRGS/2018/FTKEE-CeTRI/F00383. 


\section{REFERENCES}

[1] H. Islam, S. Das, T. Bose, and T. Ali, "Diode Based Reconfigurable Microwave Filters for Cognitive Radio Applications: A Review," IEEE Access, vol. 8, pp. 185429-185444, 2020, doi: 10.1109/ACCESS.2020.3030020.

[2] S. Ramkumar, and R. B. Rani, "Review on Recent Trends in Reconfigurable Microwave Filters," TEQIP III Sponsored International Conference on Microwave Integrated Circuits, Photonics and Wireless Networks (IMICPW), 2019, pp. 24-28, doi: 10.1109/IMICPW.2019.8933238.

[3] Y. I. A. Al- Yasir, N. O. Parchin, R. A. Abd-Alhameed, A. M. Abdulkhaleq, and J. M. Noras, "Recent Progress in the Design of 4G/5G Reconfigurable Filters," Electronics, vol. 8, no. 114, pp. 1-17, 2019, doi: https://doi.org/10.3390/electronics8010114.

[4] I. D. Saiful Bahri, Z. Zakaria, N. A. Shairi, and N. Edward, "A Novel UWB Reconfigurable Filtering Antenna Design with Triple Band-Notched Characteristics by Using U-shaped Coppers," Indonesian Journal Electrical Engineering and Computer Science IJEECS, vol. 14, no. 1, pp. 267-275, 2019, doi: 10.11591/ijeecs.v14.i1.pp267275.

[5] M. Kong, Y. Wu, Z. Zhuang, and Y. Liu, "Narrowband Balanced Absorptive Bandstop Filter Integrated with Wideband Bandpass Response," Electronics Letters, vol. 54, no. 4, pp. 225-227, 2018, doi: 10.1049/el.2017.4300.

[6] M. Mabrok, Z. Zakaria, Y. E. Masrukin, T. Sutikno, A. R. Othman, and N. Edward, "Switchable Dual-band Bandpass Filter Based on Stepped Impedance Resonator with U-shaped Defected Microstrip Structure for Wireless Applications," TELKOMNIKA Telecommunication Computing Electronics and Control, vol. 17, no. 2, pp. 10321039, 2019, doi: 10.12928/TELKOMNIKA.v17i2.11637.

[7] E. Sghir, A. Errkik, J. Zbitou, L. El Abdellaoui, A. Tajmouati, and M. Latrach, "A Novel Compact CPW Tunable Stop Band Filter Using A New Z-DGS-resonator for Microwave Applications," TELKOMNIKA Telecommunication Computing Electronics and Control, vol. 17, no. 5, pp. 2410-2417, 2019, doi: 10.12928/TELKOMNIKA.v17i5.12193.

[8] Y. Zhang, and J. Cai, J. Chen, "Design of Novel Reconfigurable Filter With Simultaneously Tunable and Switchable Passband," IEEE Access, vol. 7, pp. 59708-59715, 2019, doi: 10.1109/ACCESS.2019.2915092.

[9] S. Kingsly et al., "Compact Frequency and Bandwidth Reconfigurable Microwave Filter," Wireless Personal Communications, vol. 115, no. 2, pp. 1755-1768, 2020.

[10] O. O. Fares, "Log-domain Electronically-tuneable Fully Differential High Order Multi-function Filter," International Journal of Electrical and Computer Engineering, vol. 10, no. 2, pp. 1263-1272, 2020, doi: 10.11591/ijece.v10i2.pp1263-1272.

[11] S. Jeong, and J. Lee, "Frequency-and Bandwidth-Tunable Bandstop Filter Containing Variable Coupling Between Transmission Line and Resonator," IEEE Transactions on Microwave Theory and Techniques, vol. 66, no. 2, pp. 943-953, Feb. 2018, doi: 10.1109/TMTT.2017.2756963.

[12] B. A. Adoum, W. P. Wen, and M. S. Osman, "Switchable matched band-stop filter for high power interference mitigation," Asia-Pacific Microwave Conference Proceedings APMC, 2013, pp. 19-21, doi: 10.1109/APMC.2013.6695177.

[13] W. Yang, M. D. Hickle, D. Psychogiou, and D. Peroulis, "L-band high-Q tunable quasi-absorptive bandstop-to-allpass filter," IEEE MTT-S International Microwave Symposium (IMS), 2017, pp. 271-273, doi: 10.1109/MWSYM.2017.8059094.

[14] B. A. Adoum, and W. P. Wen, "Investigation of band-stop to all pass reconfigurable filter," 4th International Conference on Intelligent and Advanced Systems (ICIAS2012), 2012, pp. 190-193, doi: 10.1109/ICIAS.2012.6306185.

[15] D. Psychogiou, "Reconfigurable All-Pass-to-Bandstop Acoustic-Wave-Lumped-Element Resonator Filters," IEEE Microwave and Wireless Components Letters, vol. 30, no. 8, pp. 745-748, Aug. 2020, doi: 10.1109/LMWC.2020.3004028.

[16] K. Entesari, A. P. Saghati, V. Sekar, and M. Armendariz, "Tunable SIW Structures: Antennas, VCOs, and Filters," IEEE Microwave Magazine, vol. 16, no. 5, pp. 34-54, June 2015, doi: 10.1109/MMM.2015.2408273.

[17] Y. M. Hussein et al., "Substrate Integrate Waveguide and Microstrip Antennas at $28 \mathrm{GHz}$," Bulletin Electrical Engineering and Informatics (BEEI), vol. 9, no. 6, pp. 2462-2468, 2020, doi: 10.11591/eei.v9i6.2190.

[18] K. B. Kumar, and T. Shanmuganantham, "Wideband SIW filter for mm-wave applications," International Conference on Computer, Communication and Signal Processing ICCCSP, 2017, pp. 1-5, doi: 10.1109/ICCCSP.2017.7944075.

[19] T. G. Siang, D. P. D. Dass, S. Z. Ibrahim, M. N. A. Karim, and A. A. Dewani, "Design of Ku-Band Power Divider using Substrate Integrated Waveguide Technique," Bulletin Electrical Engineering and Informatics (BEEI), vol. 8, no. 1, pp. 172-179, 2019, doi: 10.11591/eei.v8i1.1410.

[20] T. Lee, B. Lee, S. Nam, Y. Kim, and J. Lee, "Frequency-Tunable Tri-Function Filter," IEEE Transactions on Microwave Theory and Techniques, vol. 65, no. 11, pp. 4584-4592, Nov. 2017, doi: 10.1109/TMTT.2017.2716931.

[21] J. Hinojosa, A. S. Rodenas, A. A. Melcon, F. L. M. Viviente, "Reconfigurable coplanar waveguide (CPW) and halfmode substrate integrated waveguide (HMSIW) band-stop filters using a varactor-loaded metamaterial-inspired open resonator," Materials, vol. 11, no. 39, pp. 1-17, 2018, doi: https://doi.org/10.3390/ma11010039.

[22] B. Lee, S. Nam, B. Koh, C. Kwak, and J. Lee, "K-Band Frequency Tunable Substrate-Integrated- Waveguide Resonator Filter With Enhanced Stopband Attenuation," IEEE Transactions on Microwave Theory and Techniques, vol. 63, no. 11, pp. 3632-3640, Nov. 2015, doi: 10.1109/TMTT.2015.2483495.

[23] T. Snow, J. Lee, and W. J. Chappell, "Tunable high quality-factor absorptive bandstop filter design," IEEE/MTT-S International Microwave Symposium Digest, 2012, pp. 1-3, doi: 10.1109/MWSYM.2012.6259759. 
[24] D. Deslandes, and K. Wu, "Design Consideration and Performance Analysis of Substrate Integrated Waveguide Components," 32nd European Microwave Conference, 2002, pp. 1-4, doi: 10.1109/EUMA.2002.339426.

[25] M. M. Jawad, N. N. N. A. Malik, N. A. Murad, M. R. Ahmad, M. R. M. Esa, and Y. M. Hussein, "Design of Substrate Integrated Waveguide with Minkowski-Sierpinski Fractal Antenna for WBAN Applications," Bulletin Electrical Engineering and Informatics (BEEI), vol. 9, no. 6, pp. 2455-2461, 2020, doi: 10.11591/eei.v9i6.2194.

[26] J. E. Rayas-Sanchez, and V. Gutierrez-Ayala, "A general EM-based design procedure for single-layer substrate integrated waveguide interconnects with microstrip transitions," IEEE MTT-S International Microwave Symposium Digest, 2008, pp. 983-986, doi: 10.1109/MWSYM.2008.4632999.

[27] D. Deslandes, "Design equations for tapered microstrip-to-Substrate Integrated Waveguide transitions," IEEE MTTS International Microwave Symposium, pp. 704-707, 2010, doi: 10.1109/MWSYM.2010.5517884.

[28] N. Keltouma, F. Mohammed, and A. Saghir, "Design and Characterization of Tapered Transition and Inductive Window Filter Based on Substrate Integrated Waveguide Technology (SIW)," International Journal of Computer Science Issues, vol. 8, no. 6 (3), pp. 135-138, 2011.

[29] A. Suntives, and R. Abhari, "Transition Structures for 3-D Integration of Substrate Integrated Waveguide Interconnects," IEEE Microwave and Wireless Components Letters, vol. 17, no. 10, pp. 697-699, Oct. 2007, doi: 10.1109/LMWC.2007.905592.

[30] D. M. Pozar, "Microwave Engineering Fourth Edition," John Wiley \& Sons, 2012.

[31] J. Lee et al., "Spectrum for 5G: Global Status, Challenges, and Enabling Technologies," IEEE Communications Magazine, vol. 56, no. 3, pp. 12-18, March 2018, doi: 10.1109/MCOM.2018.1700818.

[32] N. A. Shairi, B. H. Ahmad, and W. P. Wen, "Bandstop to Allpass Reconfigurable Filter Technique in SPDT Switch Design," Progress in Electromagnetics Research C, vol. 39, pp. 265-277, 2013, doi: 10.2528/PIERC13040313.

[33] N. A. Shairi, B. H. Ahmad, and P. W. Wong, "Absorptive SPDT switch design using cascaded switchable parallelcoupled stub resonator and switchable radial stub resonator," IEEE Region 10 Symposium, 2014, pp. 310-314, doi: 10.1109/TENCONSpring.2014.6863048.

[34] M. Y. Algumei, N. A. Shairi, Z. Zakaria, A. M. S. Zobilah, and B. H. Ahmad, "Analysis of Open Stub Resonator and its Application in Dual Isolation Band of SPDT Switch Design," International Journal of Electrical \& Computer Engineering IJECE, vol. 6, no. 6, pp. 2900-2910, 2016, doi: 10.11591/ijece.v6i6.11495.

[35] R. A. A. Kamaruddin et al., "A Study on the EBG and AMC on Radial Line Slot Array Structure at 28 GHz," Journal of Telecommunication, Electronic and Computer Engineering, vol. 10, no. 2-6, pp. 129-134, 2018.

[36] R. A. A. Kamaruddin, I. M. Ibrahim, Z. Zakaria, N. A. Shairi, T. A. Rahman, M. S. M. Isa, "A Study of Different Substrate Material on Air Gap Radial Line Slot Array (RLSA) Antenna at 28 GHzm," Journal of Telecommunication, Electronic and Computer Engineering, vol. 12, no. 1, pp. 1-5, 2020.

\section{BIOGRAPHIES OF AUTHORS}

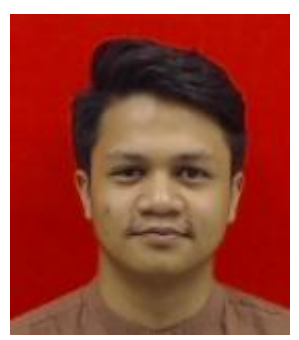

Amirul Aizat Zolkefli was born in Malaysia in 1996. He is a postgraduate student pursuing his Master's degree in Electronic Engineering at Universiti Teknikal Malaysia Melaka (UTeM). His research interest is in RF and Microwave Engineering. Currently, he is doing research on SPDT switch by using discrete PIN diode and switchable SIW resonator for 5G millimeter wave communication.

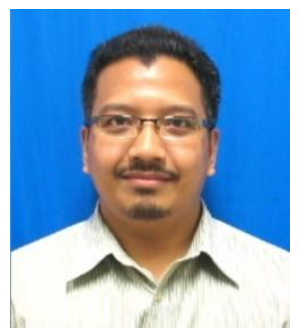

Noor Azwan Shairi was born in Malaysia. He received the Bachelor in Engineering (Electrical-Telecommunication) and the Master in Electrical Engineering from Universiti Teknologi Malaysia (UTM), in 2002 and 2005, respectively. In 2015, he obtained his Ph.D. degrees from Universiti Teknikal Malaysia Melaka (UTeM) in the field of Electronic Engineering ( $\mathrm{RF}$ and Microwave). He is currently a Senior Lecturer at the Fakulti Kejuruteraan Elektronik dan Kejuruteraan Komputer (FKEKK), Universiti Teknikal Malaysia Melaka (UTeM), Malaysia. His research interests are RF switches, switchable/tunable filters, microwave sensors, antennas \& resonators.

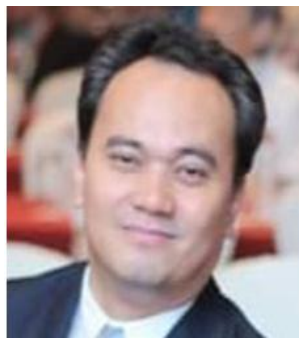

Badrul Hisham Ahmad graduated with honours degree in Electronic and Communication Engineering from the University of Leeds, UK in 1998. He received the M.Sc. degree from University Kebangsaan Malaysia in 2003 and Ph.D. degree from University of Leeds, UK for a thesis on the design and development of SIW filters in 2008. His area of interest is Advance Microwave Filters and Antenna Propagation. He is also an active researcher with a good track record with a number of research projects in RF and Microwave Engineering. He has published more than 200 journals and conference proceedings. Currently he is a Professor of Microwave Engineering in Universiti Teknikal Malaysia Melaka since 2018. 


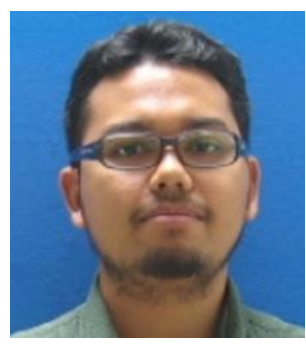

Adib Othman was born in Malaysia in 1986. He is a PhD Candidate from Universiti Tun Hussein Onn Malaysia. He received the Bachelor of Engineering (Hons) Electrical from Universiti Teknologi MARA in year 2009. In 2015, he obtained his Master of Electrical Engineering in the field of Electromagnetic Compatibility from Universiti Tun Hussein Onn Malaysia. From 2015 to 2020, he was a lecturer at Fakulti Teknologi Kejuruteraan Elektrik dan Elektronik (FTKEE), Universiti Teknikal Malaysia Melaka (UTeM), Malaysia. His research interests are mainly focused on RF and Microwave Engineering.

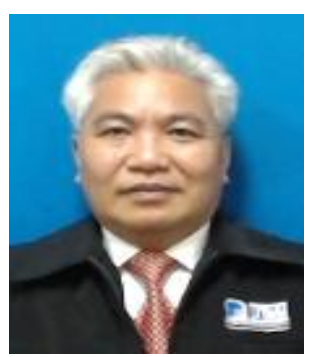

Nurulhalim Bin Hassim is a Lecturer at Universiti Teknikal Malaysia Melaka (UTeM). He received his bachelor's degree in Electircal Engineering from Lehigh University, USA in 1986. His master's degree in the same discipline was completed in 1992 at Cornell University, USA. He started his career in research and development at Motorola Malaysia in Penang in 1992. After serving for more than a decade at Motorola, working on projects ranging from radio communications upgrade for the Royal Malaysia Police and the setting up of the trunked radio system for the then brand-new Kuala Lumpur International Airport (KLIA), he moved to Dunedin, New Zealand to work at the Cadbury Chocolate Factory. He joined UTeM in 2011 to become among the pioneer instructors to setup a new Engineering Technology faculty that facilitates a more hands-on approach on studying Technical Engineering Subjects. He is currently pursuing his PhD in Radio Frequency Energy Harvesting at UTeM.

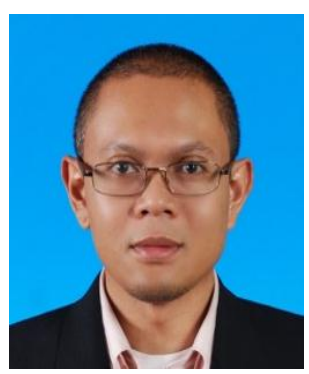

Zahriladha Zakaria was born in Johor, Malaysia. He received the B. Eng. and M. Eng. in Electrical and Electronic Engineering from the Universiti Teknologi Malaysia in 1998 and 2004 respectively, and the $\mathrm{PhD}$ degree in Electrical \& Electronic Engineering from the Institute of Microwaves and Photonics (IMP), University of Leeds, United Kingdom in 2010. From 1998 to 2002, he was with STMicroelectronics, Malaysia where he worked as Product Engineer. He is currently a Professor at Microwave Research Group (MRG), Faculty of Electronic \& Computer Engineering, University Teknikal Malaysia Melaka (UTeM). His research interests include variety of microwave devices development such as planar and nonplanar microwave filters, resonators, amplifiers and antennas. He also investigates energy harvesting and sensors. He has published more than 300 scientific papers in journals, proceedings and book-chapters. He holds 8 intellectual property rights and he has won several awards including gold medal during several research and innovation exhibitions at the national and international level. Dr. Zakaria is an active reviewer for prominent journals.

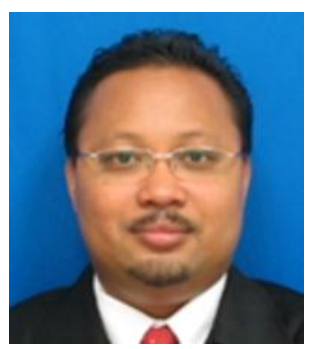

Imran Bin Ibrahim is Senior Lecturer at Universiti Teknikal Malaysia Melaka and now serve as Head of Microwave Research Group. He received his bachelor, master and doctoral degree from Universiti Teknologi Malaysia, all in electrical engineering, in 2000, 2005, and 2016, respectively. He served as faculty's first Deputy Dean (Research and Post Graduate Study) and contributed to the early development of research activities at faculty and institution. He has lead several grants from industry, government and university in antenna research and wireless communication. He is also a committee member to draft the Technical Code in 5G Safety Radiation to Malaysia Technical Standard Forum Berhad. He has published more than 70 journals and conference papers. His research interests are antennas and propagations He also supervised a $\mathrm{PhD}$ and Master students by research in antenna design for 5G and medical application.

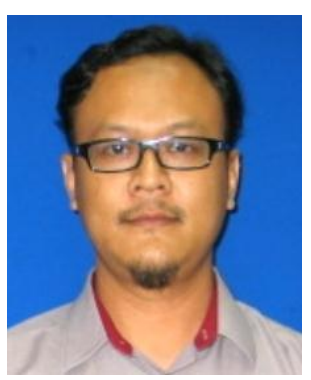

Huda Bin A Majid received the Ph.D. degree in electrical engineering from the Universiti Teknologi Malaysia (UTM). He worked as a Postdoctoral Fellow with UTM for a period of one year. He is currently a Senior Lecturer with the Faculty Engineering Technology, Universiti Tun Hussein Onn Malaysia (UTHM), Johor, Malaysia. He has published over 100 articles in journals and conference papers. His research interests include planar and flexible antennas, array antennas, reconfigurable antennas, metamaterial, and RF microwave and $\mathrm{mm}$ wave devices. 